\title{
INTERNATIONAL CONFERENCE ON THE ORIENTING REFLEX IN HUMANS
}

From June 4th through June 9th, 1978, an international conference on the orienting reflex in humans will be held at the Leeuwenhorst Congress Center, The Netherlands. The conference is sponsored by the Scientific Affairs Division of the North Atlantic Treaty Organization. The program will contain both invited theoretical papers and shorter research papers. All papers will be in English. Among the topics to be covered are: (1) theory and mechanisms of the orienting reflex; (2) methodology and measurement of the orienting reflex; (3) dynamics of the orienting reflex; (4) the orienting reflex in conditioning, attention, and perception; and (5) psychological implications of the orienting reflex and individual differences.

Abstracts ( 300 words) of submitted research papers should be submitted no later than December 1, 1977, to Professor H. D. Kimmel, Department of Psychology, University of South Florida, Tampa, Florida 33620. 